\title{
La Ética Periodística en el tratamiento informativo de la inmigración
}

\author{
M. ${ }^{a}$ del Mar López TALAVERA *
}

Propuesto: 23 de marzo de 2012

Evaluado: 20 de abril de 2012

Aceptado: 5 de mayo de 2012

(Abstracts y palabras clave al final del texto)

\section{INTRODUCCIÓN: ESTADO ACTUAL DE LA INMIGRACIÓN EN LOS MEDIOS}

En los años setenta del siglo pasado, llegaron a España unos pocos inmigrantes que resultaban por aquel entonces atractivos y novedosos y que eran identificados como turistas. En los años ochenta, asistimos a una gran afluencia de inmigrantes magrebíes para trabajar en el campo y desempeñar tareas de recogida de frutas y verduras. A finales de los ochenta y principios de los noventa, los sudamericanos comenzaron a irrumpir en el panorama nacional, y más tarde llegaron senegaleses, nigerianos, etc. que se iniciaron a trabajar en los invernaderos o en las obras públicas y últimamente aparecen en el escenario español los europeos del Este.

A partir de la década de los 90, el fenómeno de la inmigración se convirtió en un foco importante de atención mediática pasando a formar parte de la agenda diaria de los medios y uno de los principales temas de la investigación sociológica española. Pero lo cierto es que, en los últimos años, la presencia de inmigrantes ha generado en la sociedad española una percepción de amenaza, que alcanza el estatus de "problema social"1, y esta negativa imagen social está muy influida por el tratamiento que los medios de comunicación otorgan a este colectivo día a día. Esta afirmación viene corroborada, en gran parte, por la visión social de que el inmigrante es aquel que viene a establecerse en el país de otro y que se apropia de lo ajeno. De hecho, existe un consenso total respecto a la idea de que la información sobre este colectivo se realiza en la inmensa mayoría de las ocasiones de modo discriminatorio, acen-

* Universidad Complutense de Madrid. mmlopezt@ccinf.ucm.es

1 Diversos estudios sobre el tratamiento informativo de los inmigrantes, tanto en España como en otros países europeos, coinciden en subrayar una visión negativa del inmigrante, que los presenta como un "problema" y una "amenaza" para la sociedad receptora. Véase: C.M. Abella, (2002): "La construcción de la inmigración como problema en la prensa escrita", Revista Sociedad y Utopia, n. ${ }^{\circ}$ 19, pp. 57-68; Sonia 
tuando en los medios esta imagen de amenaza para el conjunto de la ciudadanía española ${ }^{2}$.

Además, la actual crisis económica mundial otorga al colectivo inmigrante el triste honor de ser considerado por la población española como parte implicada en el conflicto social. Dicho colectivo se convierte ahora en uno de los culpables más directos de la recesión económica, si se hace caso al contenido de algunas informaciones que recibimos procedentes tanto de medios escritos como audiovisuales. En efecto, desde 2010 aumentan las informaciones relacionadas con el creciente temor de la población española a la competencia del colectivo inmigrante en el acceso al mercado laboral y a las prestaciones sociales. Prueba de ello, una pequeña muestra de titulares recopilados en prensa: "Tres de cada cuatro españoles a favor de endurecer las leyes de inmigración" (El País, 2-III-10); "Casi la mitad de los españoles tiene una primera imagen negativa de la inmigración" ( $A D N, 2-\mathrm{III}-10)$; "La crisis económica radicaliza a la sociedad en contra de la inmigración" (El Pais, 3-III-10) o "La crisis sube el rechazo a los inmigrantes y la demanda de leyes más duras" (20 minutos, 2-III-10). En definitiva, que la actual crisis ha elevado el rechazo de la población española hacia los inmigrantes, cuyo número considera "excesivo" y ha acrecentado su demanda de políticas migratorias más restrictivas. Sin embargo, los problemas surgidos de la coyuntura económica pertenecen a toda la sociedad y no a un único grupo social.

Otro rasgo que también influye en la actitud que mantiene la sociedad española hacia el fenómeno migratorio es el del origen o la nacionalidad de los inmigrantes. En su investigación, Cea d'Ancona ${ }^{3}$ detecta que el grupo marroquí es el peor valorado y el referente en la mente del público a la hora de pensar en la inmigración como problema, de acuerdo con los datos sociológicos del CIS. Las noticias que se refieren a inmigrantes africanos siempre los encuadran en la imagen negativa de la llegada irregular de este colectivo en pateras. En sentido contrario, se observa cómo la actitud de los españoles en general es más positiva hacia los inmigrantes procedentes de la Unión Europea y de Latinoamérica, quizá por la percepción de compartir, a grandes rasgos, una cultura similar.

Fernández Parrat, (2005): "La inmigración en los medios de comunicación españoles", Revista Mexicana de Comunicación, en http://www.mexicanadecomunicacion.com.mx/Tables/RMC/rmc96/inmigracion.html;

Mary Nash, (2005): Inmigrantes en nuestro espejo. Inmigración y discurso periodístico en la prensa española, Barcelona: Icaria, pp. 48-51; Enrique Santamaría, (2002): "Inmigración y barbarie. La construcción social y política del inmigrante como amenaza", Papers, n. ${ }^{\circ}$ 66. Teun Van Dijk, (2005) "Nuevo racismo y noticias. Un enfoque discursivo", en Mary Nash et al. [eds.], Inmigración, género y espacios urbanos. Los retos de la diversidad, Barcelona: Ediciones Bellaterra, p.40.

2 Si decimos "narcotráfico", "bandas", "mafias", "blanqueo de dinero", "terrorismo internacional", pensamos más en extranjeros que en nacionales, el espectador lo asocia con amenazas que vienen de fuera. Por tanto, el propio enfoque de partida es inmigración = problema, amenaza. Véanse los siguientes estudios: Juan Igartua et al., (2005): "La inmigración en la prensa española. Aportaciones empíricas y metodológicas desde la teoría del encuadre noticioso", Migraciones, n. $^{\circ}$ 17; Pedro Roncal Ciriaco, (2006): "Tratamiento informativo en televisión de la inmigración hacia España", Sala de Prensa, Web para profesionales de la Comunicación Iberoamericanos, $\mathrm{n}^{\circ}$ 89. Consultado en: http://www.saladeprensa.org/art663.htm; Teun Van Dijk, (2003): Dominación étnica y racismo discursivo en España y América Latina, Barcelona: Gedisa.

3 María Ángeles Cea D’Ancona, (2004): La activación de la xenofobia en España. ¿Qué miden las encuestas?, Madrid, CIS/Siglo Veintiuno Editores. 
El tratamiento informativo de la inmigración en países europeos y latinoamericanos también ha jugado un papel esencial en el desarrollo de actitudes prejuiciosas a través de discursos racistas que tradicionalmente se han asociado contra determinados grupos étnicos ${ }^{4}$.

Esta situación nos lleva a reflexionar si en la práctica periodística los medios de comunicación tienen gran parte de la responsabilidad profesional y ética en la difusión de una imagen negativa, conflictiva y estereotipada de la inmigración. No podemos obviar que el tratamiento informativo del hecho migratorio presenta hoy en día gran complejidad y por ello se requiere de periodistas especializados en temas de inmigración.

A la vista de todo lo anteriormente expuesto, el objetivo principal de este estudio es arrojar posibles mejoras y soluciones en el tratamiento informativo del hecho migratorio. En esta aportación final, a modo de decálogo, que sirva de guía y propuesta de buenas prácticas profesionales para la correcta elaboración de informaciones referidas a este colectivo, reside el valor y originalidad de esta investigación. A tal efecto, y en relación con el objetivo principal, se definen otros objetivos que sirven de hilo expositivo argumental a todas estas reflexiones:

1. ¿Cuál es la imagen que actualmente proyectan los medios del inmigrante? Se analizarán los frecuentes estereotipos que los medios propagan en torno a la inmigración; se reflexiona en torno al nocivo binomio que relaciona inmigración y delincuencia; la imagen de la mujer inmigrante también es preocupante y se profundizará en el tratamiento audiovisual del fenómeno migratorio.

2. A la vista de la imagen negativa anteriormente descrita, se pretenden constatar todos los posibles errores y fallos, a nivel de Deontología y Ética Profesional, en el tratamiento informativo del hecho migratorio.

3. Aunque en la práctica periodística cotidiana se obvien planteamientos deontológicos en el tratamiento informativo de la inmigración, hay que señalar que existe un contenido doctrinal sobre inmigración ampliamente desarrollado en los códigos deontológicos y en los manuales de estilo de los distintos medios de comunicación. Por esta razón, es un objetivo importante señalar referencias muy concretas al colectivo inmigrante desde el campo de la Deontología Profesional.

\section{LA IMAGEN DEL INMIGRANTE EN LOS MEDIOS}

Los inmigrantes no sólo están mediáticamente mal representados, sino que, por lo general, suelen ser invisibles, algo que se debe a la mala información, en el sentido de distorsionada, que se viene difundiendo sobre ellos desde años atrás. Además,

\footnotetext{
4 Esta temática ha sido abordada en estudios del ámbito europeo y latinoamericano tales como: Fernando Checa, (2008): Personas entre dos mundos: la migración imaginada en la prensa ecuatoriana, Ecuador: Aler; Travis Dixon, (2000): "A social cognitive approach to studying racial stereotyping in the mass media", African American Research Perspectives, vol. 6, n. ${ }^{\circ}$ 1; Goran Goldberger, (2004): "Portrayal of inmigrants in newsmagazines", Migracijske i etnicke teme, vol. 1, n. ${ }^{\circ}$ 20, pp. 7-27; Jean Seaton, (2005): Carnage and the Media. The making and breaking of news about violence, Londres, Penguin Books; Teun Van Dijk (2003): Dominación étnica y racismo discursivo en España y América Latina, Barcelona: Gedisa.
} 
en las pocas ocasiones en que son objeto de atención mediática, las informaciones sobre este colectivo están relacionadas con hechos negativos ${ }^{5}$. Si hay algo positivo en la actuación y en la vida cotidiana de los inmigrantes, eso no transciende a los medios de comunicación, no es noticia. Toda esta situación descrita conlleva a que se creen visiones socialmente estereotipadas y negativas de dichos colectivos.

Existen cuatro estereotipos muy frecuentes propagados en los medios de comunicación españoles en torno a la inmigración: el primero es que los inmigrantes son muchos; el segundo, que tienen dificultades para la integración en la sociedad española, y esto afecta a unas nacionalidades más que a otras; el tercer estereotipo es que los inmigrantes inciden en el aumento de la delincuencia y el cuarto, que repercuten en el desempleo de la población activa española 6 .

Particularmente grave, por nocivo e hiriente, es el discurso informativo y político que establece una relación directa, indisociable y generalizada entre inmigración y delincuencia ${ }^{7}$, en tanto que se le relaciona con redes ilegales, crímenes, ajustes de cuentas, narcotráfico, conflictos culturales o una situación de irregularidad administrativa. Prueba de esta afirmación es un valioso ejemplo a toda página en un diario de ámbito nacional, que titula: "Estos son los inmigrantes que no quiere el pueblo español", e incluye más de una docena de fotos tamaño carnet de inmigrantes que han delinquido ${ }^{8}$. Es evidente que hay problemas de delincuencia y que además de los autóctonos hay extranjeros delincuentes, pero no es justo ni verdadero extrapolar a los millones de extranjeros residentes en nuestro país el tratamiento de delincuentes. Tampoco se puede estigmatizar, al extender la responsabilidad del delito que comete un delincuente a todo el colectivo étnico al que pertenece.

Otra imagen muy frecuente en los medios es la que presenta al inmigrante como víctima, en tanto que se vulneran sus derechos, es agredido o excluido, en ocasiones es una persona desvalida y desesperada, que está dispuesta a todo por sobrevivir y, en consecuencia, que no es muy de fiar. Desde luego que no parece ser ésta la fórmula más adecuada para profundizar en la convivencia pacífica, en la tolerancia y en los valores democráticos de una sociedad. No olvidemos el principio de ética periodística que aboga que el periodista sea promotor de la convivencia pacífica y los valores democráticos de una sociedad.

La imagen de la mujer inmigrante en los medios escritos y audiovisuales es todavía más preocupante. A pesar de la elevada presencia de mujeres entre la población inmigrante en España, las referencias mediáticas a este colectivo son mínimas. Tal y

5 En España, el Observatorio de Inmigración y Racismo ha registrado que el fenómeno de la inmigración es evaluado negativamente porque son frecuentes los temas sobre las tragedias de los migrantes y los artículos sobre tráfico de inmigrantes. Otros temas recurrentes son la delincuencia atribuida a los inmigrantes, la prostitución y la violencia entre inmigrantes.

6 O. Vázquez, (1999): "Negro sobre blanco: inmigrantes, estereotipos y medios de comunicación", Comunicar, n. ${ }^{\circ} 12$, , pp. 55-60.

7 El encuadre que vincula inmigración con delincuencia puede consultarse en: Juan José Igartua Perosanz y Carlos Muñiz Muriel, (2004): "Encuadres noticiosos e inmigración. Un análisis de contenido de la prensa y televisión españolas", Zer. Revista de Estudios de Comunicación, n. ${ }^{\circ}$ 16, pp. 87-104; Juan José Igartua Perosanz, et al., "La inmigración en la prensa española..." op. cit., pp. 143-181.

8 Diario La Razón, 15 de febrero de 2002. Portada y Págs. 4 y 47-49. 
como señala Mary Nash, "el discurso periodístico evidencia una práctica discursiva de negación de protagonismo al colectivo de mujeres inmigrantes". "Es más, cuando éstas aparecen frecuentemente están asociadas a conflictos, agresiones, violencia de género o prostitución" 9 .

Con respecto al tratamiento audiovisual del fenómeno migratorio en los informativos encontramos una imagen frecuente: la del horror, la desesperación, la tragedia del inmigrante. Las imágenes de pateras, guardias civiles reconduciendo a los que han conseguido sobrevivir, los cuerpos de los que han muerto en las playas, la proliferación de estas marcadas situaciones ahonda en la imagen descompensada, dramática, trágica de la inmigración. Ejemplos ilustrativos extraídos de una muestra de telediarios analizados demuestran esta imagen de la inmigración:

- Continúa la oleada de cayucos a las costas de Gran Canaria (Canal 9, 11/11/2007).

- En las costas andaluzas nueva oleada de inmigrantes. Se han contabilizado más de 300 inmigrantes ilegales a lo largo de este fin de semana. A Motril llegaba esta otra patera y a Canarias llegaban de madrugada nuevos cayucos con subsaharianos a bordo. El buen tiempo ha facilitado la avalancha de las últimas horas (Antena 3, 11/11/2007).

- Otra gran patera. Doscientos inmigrantes han llegado en patera a las costas canarias en las últimas 48 horas (TVE1, 10/11/2007).

- A pesar del frío, siguen llegando cayucos a Canarias. El último esta noche (TVE1, 01/12/2007).

- En pleno invierno, la llegada de pateras a nuestras costas no cesa (Canal 9, 09/01/2008).

Indudablemente el dolor está ahí y no se puede obviar, pero la cantidad de veces que se ofrecen en los telediarios estas imágenes supone un salto cualitativo en la percepción negativa de la inmigración como problema y drama humano. Y hay que constatar que el concepto de emigrar por sí mismo no es sinónimo de dolor. Afortunadamente, también en la vida del extranjero se combinan momentos de esperanza, de alegría, de ilusión por un nuevo proyecto de futuro.

En definitiva, que la inmigración no está teñida únicamente de negro como los medios de comunicación nos quieren mostrar a diario. Y no se puede mostrar en los medios una única inmigración, unida al horror y al dolor, ni una única manera de sufrir en un proceso migratorio. Por tanto, si se ofrecen noticias negativas en torno al colectivo inmigrante hay que ofrecer también lo positivo que puedan estar aportando a la sociedad receptora para equilibrar su imagen y no generar tendenciosidad. No olvidemos que el inmigrante, en la mayoría de los casos, es un sujeto activo, con un proyecto migratorio propio y con una identidad personal. Hay que lamentar que sólo en contadas ocasiones y de manera excepcional, se escuche en los medios la voz del inmigrante, testigo directo y protagonista principal de la noticia. En líneas gene-

9 Mary Nash, op.cit., pp. 104; 140. 
rales, los medios deberían presentar al colectivo inmigrante como lo que es en su mayoría: trabajador e integrado en la sociedad española.

Los media tienen la responsabilidad social de no simplificar la compleja realidad de la inmigración, de no alimentar los estereotipos, actitudes o percepciones que favorezcan el conflicto y dificulten la convivencia ${ }^{10}$.

\section{FALLOS ÉTICOS EN EL TRATAMIENTO INFORMATIVO DE LA INMIGRACIÓN}

En líneas generales, la información relacionada con el colectivo de inmigrantes sirve a intereses políticos y los medios suelen enfocar estas noticias con un cierto tono paternalista, que no siempre refleja un auténtico interés por la situación real de los inmigrantes.

Los inmigrantes aparecen mal reflejados en las noticias: por regla general, la voz de los inmigrantes no está presente en los medios. En todo caso, hablan por ellos otras personas. De esta forma, difícilmente son identificados con nombres y apellidos a no ser que sean agresores individuales o víctimas de alguna forma de violencia o agresión. Por tanto, son demasiadas las ocasiones en las que únicamente tienen visibilidad y trascendencia cuando protagonizan sucesos negativos. Los medios aprovechan estos sucesos dramáticos que están relacionados con este colectivo y los sobredimensionan. De esta manera, alimentan el morbo y ganan más audiencia, incumpliendo el principio de ética periodística que aboga por erradicar el sensacionalismo en las informaciones. La aparición constante en los informativos de televisión de noticias duras o tristes sobre inmigrantes provoca que éstos estén constantemente en el punto de mira de la opinión pública, creándoles una imagen desfavorable. No hay que olvidar la influencia y el poder que ejerce la TV, que es extraordinaria; por tanto el daño que puede hacerse es brutal con la utilización de estereotipos, tales como "invasor", "problemático", "conflictivo", "delincuente", "violento", "enfermo", "pobre", etiquetas todas desacreditadoras y términos peyorativos que favorecen la estigmatización y segregación de este colectivo. Además, la inmigración sigue planteándose en los medios como un problema, en el que se alienta lo polémico y se silencia la normalidad.

Otro fallo generalizado en el tratamiento informativo de la inmigración es el uso continuo de eufemismos que no logra aliviar o cambiar los estereotipos generados. En efecto, al sustituir la palabra "negro" por "persona de color" no se lucha contra la discriminación que sufren. Igualmente, es denunciable el uso generalizado de "coletillas" relacionadas con la condición del inmigrante en función de la nacionalidad, la etnia y el género. No hay que olvidar el principio de ética periodística que defiende que el comunicador social o el periodista no deben hacer discriminación

10 A. Granados, (2007): “La realidad narrada y la realidad opinada de la inmigración”, en Juan José Igartúa; Carlos Muñiz, Medios de comunicación, inmigración y sociedad, Salamanca, Ed. Universidad de Salamanca, p. 44. 
alguna en sus escritos o noticias audiovisuales en función de la raza, la nacionalidad, el género, la religión o cualquier otra razón de índole política o ideológica.

De los diversos estudios monográficos consultados, se destacan cinco errores fundamentales como los más reiterados por los medios en el tratamiento informativo de la inmigración ${ }^{11}$. Éstos son:

1) El carácter de avalancha: desde los medios de comunicación se instala en la opinión pública la idea de que nuestro país está sometido a una auténtica "invasión", facilitada por la situación geográfica que la convierte en frontera Norte-Sur. De ahí las imágenes continuas de pateras sobrecargadas de seres humanos, cuando sólo representan un pequeño porcentaje de la entrada irregular en el país. El uso habitual de términos como "avalancha", "oleada" o "marea" para referirse a la llegada a nuestro país de extracomunitarios se trata de una metáfora inquietante.

2) Peligro para la sociedad de acogida: las condiciones precarias de vida de los países exportadores de inmigrantes hace que surja en nuestra sociedad de acogida el temor a que se extiendan diferentes enfermedades y también que se instalen pautas culturales consideradas inapropiadas.

3) Carácter delictivo: puesto que tenemos el concepto propiciado por los medios de que los inmigrantes entran en nuestro país, en su mayoría, de forma ilegal, esta situación a su vez favorece el establecimiento de redes de delincuencia y criminalidad. Se genera en la mente de los receptores de los informativos un claro binomio: ilegalidad $=$ delincuencia. Pero hay que decir que la inmigración, por sí misma, no genera delincuencia. Y no lo hace porque básicamente la inmigración es un concepto laboral. Al que viene a cometer delitos sin permiso de residencia no se le puede llamar inmigrante, sino delincuente transfronterizo ${ }^{12}$.

4) Precariedad y marginalidad: como consecuencia también del carácter irregular de la inmigración, se crean importantes bolsas de pobreza y marginalidad entre este colectivo.

5) Ausencia de la mujer inmigrante: está completamente ausente en TV, informativamente la mujer inmigrante no existe. Es más, cuando las mujeres inmigrantes aparecen en los medios lo hacen a menudo como víctimas, en la mayoría de los casos se las relaciona con la prostitución. Poco se refleja en los medios de las mujeres inmigrantes que trabajan como empleadas del hogar o cuidando ancianos.

A la vista de todos estos fallos en el tratamiento informativo sobre la inmigración, se puede concluir que los medios no han adoptado una postura responsable ni coherente en la cobertura de este tema. Las noticias referentes a este colectivo se

11 José Alberto García Avilés; Irene Bernal Carcelen, (2006): "El tratamiento de la inmigración en los informativos televisivos", Revista de la Facultad de Ciencias Sociales y Jurídicas de Elche, n. ${ }^{\circ}$ 1, pp. 80-91.

12 F. García-Calabrés, (2009): Inmigrantes en España. Claves para comprender un fenómeno mundial, Madrid, Laberinto, pp. 56-57. 
ofrecen de forma descontextualizada: cuando se habla de inmigrantes se les llama ilegales, como si todos procedieran del mismo contexto, como si todos tuvieran idéntica condición jurídica. Además, predomina el uso de titulares exagerados en los que abunda la hipérbole y la ridiculización, sobre todo con el fin de desacreditar a este grupo mediante la intensificación de su imagen y rasgos negativos. Se aprecia, en definitiva, un descuido del lenguaje, en ocasiones, inapropiado. Los medios de comunicación han incumplido prioritariamente el principio de ética periodística que aboga por la responsabilidad profesional del informador, que debe servir a un interés común o bien público por encima de intereses particulares, empresariales o de mercado.

\section{CONTENIDO DOCTRINAL SOBRE INMIGRACIÓN EN LOS CÓDIGOS DEONTOLÓGICOS Y MANUALES DE ESTILO}

Con respecto a la inmigración, los códigos deontológicos adquieren vital importancia como un freno a las malas prácticas periodísticas y una reflexión clara de la función del periodista en una sociedad multicultural. Por su parte, recogen principios fundamentales que atañen muy especialmente a este colectivo tan claramente desfavorecido como el principio de informar con imparcialidad y rigor, o el de informar con verdad, objetividad y exactitud, el deber de contrastar las fuentes informativas y otros muchos más.

Son innumerables las iniciativas a nivel nacional y a nivel local de las que han surgido decálogos o recomendaciones para el buen tratamiento de la inmigración. La Federación de Asociaciones de Periodistas de España (FAPE) en su Código Deontológico de la Profesión Periodística ${ }^{13}$ sólo recoge en el artículo 7 alguna referencia a la discriminación. Lo hace de este modo:

7. El periodista extremará su celo profesional en el respeto a los derechos de los más débiles y los discriminados (...)

a) Debe, por ello, abstenerse de aludir, de modo despectivo o con prejuicios a la raza, color, religión, origen social o sexo de una persona o a cualquier enfermedad o minusvalía física o mental que padezca.

b) Debe también abstenerse de publicar tales datos, salvo que guarden relación directa con la información publicada.

En Andalucía, un documento de referencia es Inmigración e Información. Recomendaciones para periodistas, editado por la Asociación de la Prensa del Campo de Gibraltar. Este documento, que ha sido asumido por la Federación de Asociaciones de Periodistas de España (FAPE), defiende el derecho a la dignidad del inmigrante y recuerda que el inmigrante no es un mero número. Y el periodista,

13 Fue adoptado por la Federación de Asociaciones de la Prensa de España (FAPE) el 27 de noviembre de 1993. Puede consultarse en:

http://www.fape.es/index.php?option=com_content\&task=view\&id=101\&Itemid=120. 
siempre que pueda, deberá esforzarse por conocer sus circunstancias y las razones que le llevaron a emigrar. Además, la Federación Andalucía Acoge ha difundido folletos con ocho propuestas para tratar la inmigración con corrección y orientar al periodista en el uso de un lenguaje adecuado. Por su parte, el Consejo Audiovisual de Andalucía ${ }^{14}$ recoge recomendaciones específicas sobre el tratamiento de la inmigración tales como favorecer la especialización y formación permanente del periodista, con objeto de eludir una terminología basada en estereotipos y en un lenguaje discriminatorio. En este sentido, no deben usarse expresiones como "ilegales" o "sin papeles". Además, el consejo andaluz defiende huir de la magnificación y la generalización y hacer el esfuerzo de informar para comprender y no para juzgar.

Cataluña es una región prolífera en recomendaciones para el correcto tratamiento de la inmigración en los medios de comunicación. Por su parte, el Colegio de Periodistas de Cataluña elaboró en 1996 un Manual de Estilo sobre minorías étnicas ${ }^{15}$ que recoge seis recomendaciones básicas. Una de ellas alude a que no hay que incluir el grupo étnico, el color de la piel, el país de origen, la religión o la cultura de los protagonistas si no es estrictamente necesario para la comprensión global de la noticia. Otra de las recomendaciones defiende la ecuanimidad en las fuentes de información, potenciando las propias fuentes de las minorías étnicas. También en su Declaración de Principios de la Profesión Periodística ${ }^{16}$, el colegio de periodistas catalanes aboga por "actuar con especial responsabilidad y rigor en el caso de informaciones u opiniones con contenidos que puedan suscitar discriminaciones por razones de sexo, raza, creencia o extracción social y cultural, así como incitar al uso de la violencia, evitando expresiones o testimonios vejatorios o lesivos para la condición personal de los individuos y su integridad física y moral". Además, el Consejo del Audiovisual de Cataluña (CAC) es explícito, exhaustivo y claro en sus Recomendaciones sobre el tratamiento informativo de la inmigración ${ }^{17}$. Consciente el CAC de que todo el esfuerzo y exigencias deben partir de los órganos gestores de las propias empresas de comunicación, el texto de recomendaciones pide a los medios colaborar en las políticas públicas de incorporación de la población inmigrada, además del establecimiento de un clima de diálogo social. Por ello, la información difundida por los medios audiovisuales no debe ser parcial, sino total y contextualizada, y debe servir a la población autóctona, pero también, tanto o más a la incorporada. La no discriminación, en sus diversas formas y manifestaciones (raza, color, origen, lengua, cultura, creencia...) depende de un buen uso y de una acertada selección de los términos a emplear en la construcción de cada frase. Las orientaciones aportadas obligan a una cuidadosa elección de vocablos. Por último, el CAC plantea unas consideraciones finales con objeto de desterrar la idea de que la inmigración es una amenaza.

\footnotetext{
14 Las recomendaciones del Consejo Audiovisual de Andalucía datan de 2005. Pueden consultarse en: http://www.consejoaudiovisualdeandalucia.es/opencms/ActuacionesDelCAA/?_locale=es.

15 Este manual fue elaborado en el año 2008 y puede consultarse en la siguiente dirección web: http://www.periodistes.org.

16 Aprobada por el Colegio de Periodistas de Cataluña, el 22 de octubre de 1992.

17 Estas recomendaciones fueron publicadas en 2001. Puede consultarse en: http://www.audiovisualcat.net/home/investigacion/inmigracion.pdf.
} 
Navarra también posee normas de autorregulación para los medios de comunicación y en todas ellas mantiene la apuesta por fomentar los aspectos positivos de la información de forma que ayude a desterrar el racismo y promover la integración. En sus principios, el Consejo Audiovisual de Navarra (COAN) ${ }^{18}$ afirma que los medios deben tomar partido, de manera explícita, clara y unánime, a favor de los derechos humanos y la difusión de la tolerancia. Por tanto, los medios no deben solo limitarse a ser un reflejo de los acontecimientos, sino que deberían buscar la educación de la población y su comprensión hacia el fenómeno de la inmigración. Cualquier decisión profesional debe descartar el uso de estereotipos, excluir comportamientos xenófobos, superar la mera convivencia entre autóctonos y emigrantes y fomentar la integración y cohesión social. Para lograrlo, el COAN recomienda abandonar el tono negativo que se transmite al abordar la inmigración como un asunto referido únicamente a la llegada de ilegales.

En cuanto a los documentos internos de los medios impresos, en el Libro de Estilo ${ }^{19}$ del periódico El País puede advertirse alguna referencia concreta relativa a la inmigración. En su inicio, y bajo el epígrafe de "expresiones malsonantes" dice lo siguiente: "Nunca deben utilizarse palabras o frases que resulten ofensivas para una comunidad. Por ejemplo, "le hizo una judiada", "le engañó como a un chino", "eso es una gitanería". En el Estatuto de Redacción ${ }^{20}$ del diario El Mundo se halla una referencia a las minorías: "El Mundo será especialmente sensible a los derechos de las minorías". No obstante, es en su Libro de Estilo ${ }^{21}$ donde se aborda el tema que nos ocupa de forma pormenorizada, introduciendo un interesante apartado sobre "expresiones racistas o de supremacía étnica, social o religiosa".

Por su parte, el diario de mayor difusión en Cataluña, La Vanguardia, en su Libro de Redacción ${ }^{22}$ coloca alfabéticamente un glosario de términos donde define claramente qué se debe entender por una persona de color, etnia, ilegal, magrebí, mahometano y moro entre otros vocablos. El Grupo Vocento en su Libro de Estilo ${ }^{23}$, en el apartado de los principios periodísticos, defiende que "el periodista no discriminará a ninguna fuente por razones sociales, políticas, raciales, religiosas, de sexo, etcétera". Por último señalar que el Estatuto de Redacción ${ }^{24}$ de la Agencia EFE, en su artículo 9, se pronuncia de la siguiente manera: "El tratamiento del material informativo de EFE evitará cualquier tipo de discriminación por razones de religión, origen, situación social, cultura, etnia, sexo o cualquier enfermedad o discapacidad". Y en su artículo 15, "EFE tratará de dar voz a personas y colectivos afectados por alguna forma de exclusión social".

18 El Consejo Audiovisual de Navarra aprobó su normativa en 2006. Puede consultarse en: http://consejoaudiovisualdenavarra.es/actuaciones/recomenda.htm.

19 El País, Libro de Estilo, Madrid, Santillana, 2003.

20 Acordado el 5 de diciembre de 1990. Puede consultarse en:

http://www.fesp.org/docs/EstatutoElMundo.pdf.

21 El Mundo, Libro de Estilo, Madrid, Unión Editorial/Temas de hoy, 1996.

22 La Vanguardia, Libro de Redacción, Barcelona, Ariel, 2004.

23 José Martínez de Sousa, Libro de Estilo Vocento, Gijón, Trea, 2003.

24 Texto aprobado el 22 de marzo de 2006. Puede consultarse en: http://efe.com/FicherosDocumentosEFE/estatuto.pdf. 
En cuanto a recomendaciones específicas sobre el tratamiento de la inmigración en los medios audiovisuales, en radio destaca el Libro de Estilo ${ }^{25}$ de la Cadena COPE. En el mismo se advierte que las noticias que difunden sus servicios informativos "no harán mención a la raza de las personas de las que se informa, a no ser que tenga una relación directa con el fondo de la información".

Por imperativo legal, todas las cadenas de televisión, tanto públicas como privadas, para cualquier ámbito de difusión, están obligadas a reconocer y practicar la no discriminación en los contenidos, muy especialmente en sus espacios informativos. Por su parte, Televisión Española, refleja taxativamente la no discriminación en sus Principios Básicos de la Programación de RTVE26. En alusión directa a las minorías e inmigrantes, el acuerdo determina que "RTVE mantendrá una actitud vigilante a fin de impedir la transmisión de contenidos que explícita o implícitamente justifiquen o alienten el racismo y la xenofobia. RTVE promoverá la producción de contenidos específicos que expresen el respeto debido a las minorías y aseguren su presencia en la programación, con especial atención a la integración de los inmigrantes (...)".

Canal Sur Televisión y Canal 2 Andalucía están comprometidos profundamente con las minorías y la no discriminación a través de los principios de programación y del Libro de Estilo, donde proliferan recomendaciones de obligado seguimiento sobre emigración, racismo y xenofobia.

La Corporación Catalana de Radio y Televisión (CCRTV) en sus Principios de Actuación ${ }^{27}$ recuerda que la inmigración debe verse reflejada en los medios de comunicación desde una óptica positiva, sin faltar a la veracidad informativa.

Radio Televisión Valenciana (RTVV) en su Estatuto Profesional de la Redacción 28 anuncia que "acogerá todas las tendencias, excepto aquellas que propugnen la violencia, la xenofobia, el racismo o cualquier otra actitud inconstitucional para el cumplimiento de sus finalidades".

En resumidas cuentas y tras examinar a fondo todos los documentos y declaraciones precedentes, se puede constatar que el principal objetivo de todas las recomendaciones y advertencias contenidas en los códigos de ética y manuales de estilo sobre el tratamiento informativo de la inmigración apuntan hacia el compromiso del periodista para poner unos límites a la forma de informar sobre este colectivo tan desfavorecido y tan discriminado. Los códigos de ética señalan la responsabilidad que tienen los medios con la sociedad y la necesidad de dar una igualdad de tratamiento, eliminando prácticas discriminatorias, en referencia a la inmigración. En definitiva, los criterios de estos documentos son muy similares y coinciden básicamente en evitar el uso de un lenguaje inadecuado, por resultar discriminatorio y fuera de contexto, así como no relacionar la inmigración con el delito, contrastar las

\footnotetext{
25 Cadena COPE, Libro de Estilo, Logroño, Cadena COPE, 2003.

26 Los Principios Básicos de la Programación de RTVE fueron aprobados el 13 de junio de 2007.

27 Los Principios de Actuación de la CCRTV fueron actualizados el 28 de marzo de 2006. Pueden consultarse en: http://www.ccrtv.cat/regulacio/regulacio_principis_actuacio_cas.htm.

28 RTVV aprobó su Estatuto Profesional de la Redacción el-19 de septiembre de 1996. Puede consultarse en: http://www.rtvv.es/rtvv/estatuc.asp.
} 
fuentes y procurar dar voz propia a los inmigrantes y, sobre todo, favorecer los aspectos positivos de la inmigración.

\section{CONCLUSIONES}

Tras analizar detenidamente el tratamiento informativo de la inmigración en prensa, radio y televisión, la primera conclusión general que puede extraerse es que es negativo y que carece de la calidad informativa necesaria porque en todos los medios analizados, el colectivo de inmigrantes no es más que una cifra, no tiene voz propia ni identidad. Dicho tratamiento, sigue planteándose en los medios de comunicación españoles, con aspectos peyorativos y con un fuerte desprestigio hacia este hecho social.

Además, la representación mediática de la inmigración desde hace varios años ha podido contribuir al florecimiento de estereotipos y prejuicios y ha impactado de forma concreta en la poca simpatía de los españoles hacia determinados colectivos de inmigrantes, tales como los marroquíes, muchas veces asociados a una auténtica invasión o los rumanos, relacionados con violencia, delitos y redes ilegales de extorsión, en definitiva, colectivos que muchas veces se consideran una amenaza real para la sociedad española.

También es criticado un uso excesivo por parte de los medios de figuras retóricas como "oleada", "avalancha", "marea", para describir el fenómeno migratorio. Es más, en los telediarios y en la prensa diaria se produce una constante problematización de las migraciones, ya sea porque invaden nuestras costas, o bien desarrollan actividades criminales o su presencia en España está ligada a numerosas dificultades de integración, de pobreza, de problemas culturales, etc. Lo que sí parece claro es que hay una evidente tendencia al sensacionalismo periodístico por la permanente necesidad de llamar la atención y magnificar la información sobre inmigración con objeto de acaparar más lectores o audiencia.

Otra conclusión importante se extrae del análisis de los códigos deontológicos y los manuales de estilo. En todas las recomendaciones, se establece que los periodistas extremen el respeto a los derechos de los más débiles y a los discriminados. Con el fin de combatir las imágenes negativas y desfavorables para este colectivo, los códigos éticos se pronuncian a favor de incluir rasgos específicos como la raza, la nacionalidad, la religión o el género, únicamente si éstos resultan estrictamente necesarios para comprender la información.

De hecho, surgen voces dentro del ámbito profesional y académico que abogan por un tratamiento informativo del hecho migratorio más responsable. Se apela a límites éticos en la práctica periodística puesto que los medios de comunicación tienen la responsabilidad social de no simplificar y estereotipar la compleja realidad de la inmigración y no alimentar actitudes o percepciones que favorezcan el conflicto y dificulten la convivencia. Esta responsabilidad social y ética es de los medios y no cabe transferírsela al público, la audiencia o la ciudadanía en general.

Con objeto de aportar elementos novedosos al tratamiento informativo de la inmigración, a continuación, se expone una propuesta inédita y original, basada en 
años de investigación y docencia en el campo de la Ética y Deontología Profesional, para la mejora del tratamiento ético-informativo de la inmigración.

\section{PROPUESTA DE BUENAS PRÁCTICAS PROFESIONALES PARA EL TRATAMIENTO ÉTICO-INFORMATIVO DE LA INMIGRACIÓN}

Tras considerar y valorar todos los fallos éticos que se cometen en el tratamiento informativo de la inmigración se hace necesario que los profesionales implicados en la producción informativa, tanto empresas como periodistas, hagan un esfuerzo conjunto por intentar mejorar la imagen informativa que sobre este colectivo muestran a diario.

Desde el campo de investigación en Ética y Deontología de la Información periodística, se muestra una propuesta inédita, un decálogo de buenas prácticas profesionales para el tratamiento ético de la información sobre inmigración.

1. El periodista no debe alterar o manipular la realidad informativa presuponiendo que una persona es inmigrante por el color de su piel o por su forma de vestir. Para no faltar al principio de la verdad, objetividad y exactitud en las informaciones, hay que confirmar primero su condición de inmigrante.

2. El periodista debe dar un correcto tratamiento a su fuente informativa y eso significa que no tiene que explicitar la nacionalidad o la raza de los implicados si no es estrictamente necesario para la comprensión global de la noticia.

3. El periodista debe esforzarse para encontrar, elegir y emitir informaciones desde una perspectiva positiva que contribuyan a favorecer un estado de opinión próximo a la integración social de este colectivo, cómo es su vida cotidiana y su arraigo en las distintas poblaciones. No tan sólo informar de la inmigración respecto a su entrada masiva, las mafias y otros aspectos relacionados con la delincuencia y la ilegalidad que no hacen más que transmitir una imagen negativa de los inmigrantes.

4. No hay que abusar de las imágenes de archivo para ilustrar una noticia actual sobre inmigración, menos aún abusar de las típicas imágenes de pateras puesto que crean alarmas y pánicos innecesarios en la población española y dan la sensación de que todos los inmigrantes entran en nuestras fronteras en situación irregular.

5. El periodista debe tener un especial cuidado en el uso de las imágenes de dolor y muerte. Para no discriminar, se les debe aplicar a los extranjeros el mismo trato y los mismos criterios deontológicos que a los nacionales en cuanto al respeto a su dolor y a su sufrimiento. No hay que abusar en los informativos de las tragedias humanas.

6. Para fomentar el principio de ética periodística de pluralidad e imparcialidad en las opiniones, el periodista tiene que dar voz a los inmigrantes en las distintas informaciones que les afectan y a las organizaciones que los agrupan y les representan (ONGs, asociaciones de acogida y de ayuda, etc.). 
7. El periodista no debe discriminar por razón de raza, etnia, género, creencias religiosas o de cualquier otra índole. Al respecto, el uso correcto del lenguaje es primordial para evitar términos peyorativos y discriminatorios que induzcan a estereotipos y prejuicios. Por tanto, hay que alejarse del uso de adjetivos tales como "avalancha", "oleada", "marea", "brote" y otros tantos del estilo.

8. El periodista no debe caer en el sensacionalismo periodístico que fomenta el discurso del miedo y que muestra amenazas para la población española sin datos probados. Se debe evitar a toda costa magnificar el hecho migratorio y convertir las noticias relacionadas con este fenómeno social en un espectáculo, en un reality-show.

9. Las empresas de comunicación deben adoptar una actitud responsable y activa en el fomento de la convivencia pacífica, la tolerancia y la promoción de los valores democráticos.

10. Las empresas periodísticas deben propiciar la especialización, formación permanente y actualización de los profesionales dedicados al tema de la inmigración.

\section{REFERENCIAS BIBLIOGRÁFICAS}

C.M. ABELLA, (2002): "La construcción de la inmigración como problema en la prensa escrita", Revista Sociedad y Utopía, n. ${ }^{\circ} 19$, pp. 57-68.

Agencia EFE, Estatuto de Redacción, 2006, en: http://efe.com/FicherosDocumentosEFE/estatuto.pdf. Consultado el 17/01/2012.

M.C. Albert Guardiola; E. Espinar Ruíz; M.I. Hernández SÁnchez, (2010): "Los inmigrantes como amenaza. Procesos migratorios en la televisión española", Convergencia, n. ${ }^{\circ} 53$, pp. $49-68$.

CADENa COPE, (2003): Libro de Estilo, Logroño: Cadena COPE.

M.A. Cea D’AnCona, (2004): La activación de la xenofobia en España. ¿Qué miden las encuestas?, Madrid: CIS/Siglo Veintiuno Editores.

Colegio de Periodistas de Cataluña, (1996): Manual de Estilo sobre minorías étnicas, en: http://www.periodistes.org. Consultado el 06/02/2012.

Consejo Audiovisual de ANDALucía, en: http://www.consejoaudiovisualdeandalucia.es/opencms/ActuacionesDelCAA/?_locale=es. Consultado el 09/02/2012.

CONSEjo Audiovisual De NAVARRA (COAN), 2006, en: http://consejoaudiovisualdenavarra.es/actuaciones/recomenda.htm. Consultado el 18/01/2012.

Consejo Del Audiovisual de Cataluña (CAC), Recomendaciones sobre el tratamiento informativo de la inmigración, 2001, en: http://www.audiovisualcat.net/home/investigacion/inmigracion.pdf. Consultado el 26/01/2012.

Corporación Catalana de Radio y televisión (CCRTV), Principios de Actuación, 2006, en: http://www.ccrtv.cat/regulacio/regulacio_principis_actuacio_cas.htm. Consultado el $13 / 02 / 2012$.

F. CHECA, (2008): Personas entre dos mundos: la migración imaginada en la prensa ecuatoriana, Ecuador, Aler.

T. DiXon, (2000): “A social cognitive approach to studying racial stereotyping in the mass media", African American Research Perspectives, vol. 6, n. ${ }^{\circ} 1$. 
El Mundo, Estatuto de Redacción, en: http://www.fesp.org/docs/EstatutoElMundo.pdf. Consultado el 22/02/2012.

El Mundo, Libro de Estilo, (1996): Madrid, Unión Editorial/Temas de hoy.

El País, Libro de Estilo, (2003): Madrid, Santillana.

Federación de Asociaciones de Periodistas de España (FAPE), Código Deontológico de la Profesión Periodística, en:

http://www.fape.es/index.php?option=com_content\&task=view\&id=101\&Itemid=120. Consultado el 10/01/2012.

S. FERnÁNDEZ PARRAT, (2005): "La inmigración en los medios de comunicación españoles", Revista Mexicana de Comunicación, en:

http://www.mexicanadecomunicacion.com.mx/Tables/RMC/rmc96/inmigracion.html. Consultado el 03/02/2012.

J. A. García Avilés; I. BernaL CARCElen, (2006): "El tratamiento de la inmigración en los informativos televisivos", Revista de la Facultad de Ciencias Sociales y Jurídicas de Elche, n. ${ }^{\circ}$ 1, pp. 80-91.

F. GARCÍA-CALABRÉS, (2009): Inmigrantes en España. Claves para comprender un fenómeno mundial, Madrid, Laberinto, pp. 56-57.

G. GoldBERGER, (2004): "Portrayal of inmigrants in newsmagazines", Migracijske i etnicke teme, vol. 1, n. $^{\circ} 20$, pp. 7-27.

A. GRANADOS, (2007): "La realidad narrada y la realidad opinada de la inmigración", en J.J. Igartua; C. Muñiz, Medios de comunicación, inmigración y sociedad, Salamanca: Ediciones Universidad de Salamanca.

J.J. Igartua Perosanz; C. MuÑIz Muriel,(2004): “Encuadres noticiosos e inmigración. Un análisis de contenido de la prensa y televisión españolas", Zer. Revista de Estudios de Comunicación, n. ${ }^{\circ} 16$, pp. 87-104.

La Razón, 15 de febrero de 2002, portada y pp. 4; 47-49.

La Vanguardia, Libro de Redacción, (2004): Barcelona, Ariel.

J. MARTínez de SousA, (2003): Libro de Estilo Vocento, Gijón: Trea.

C. Muñiz Muriel, J.J. Igartua Perosanz; J.M. De la Fuente; J.A. Otero Parra, (2009): "Narrando la inmigración: análisis del tratamiento informativo y evaluación de los efectos de las noticias en España", Revista Mexicana de Ciencias Políticas y Sociales, n. ${ }^{\circ}$ 207,pp. 117-135.

M. NASH, (2005): Inmigrantes en nuestro espejo. Inmigración y discurso periodístico en la prensa española, Barcelona: Icaria.

Radio Televisión Valenciana (RTVV), (1996): Estatuto Profesional de la Redacción, 1996, en: http://www.rtvv.es/rtvv/estatuc.asp. Consultado el 17/02/2012.

P. RONCAL CiRIACO, (2006): "Tratamiento informativo en televisión de la inmigración hacia España", Sala de Prensa, Web para profesionales de la Comunicación Iberoamericanos, n. ${ }^{\circ}$ 89. Consultado en: http://www.saladeprensa.org/art663.htm, el 15/02/2012.

J. SEATON, (2005): Carnage and the Media. The making and breaking of news about violence, Londres: Penguin Books.

J. F. TORREgrosa CARMONA, (2005): "El tratamiento informativo de la inmigración como paradigma de la alteridad", Pueblos. Revista de información y debate, en: http://www.revistapueblos.org/spip.php?page=imprimir articulo\&id article=996. Consultado el 01/02/2012.

T. VAN DiJK, (2003): Dominación étnica y racismo discursivo en España y América Latina, Barcelona: Gedisa.

, (2005): "Nuevo racismo y noticias. Un enfoque discursivo", en M. Nash et al. [eds.], Inmigración, género y espacios urbanos. Los retos de la diversidad, Barcelona: Ediciones Bellaterra. 
O. Vázquez, (1999): "Negro sobre blanco: inmigrantes, estereotipos y medios de comunicación", Comunicar, n. ${ }^{\circ} 12$, pp. 55-60.

B. Zalbidea; J.C. Pérez Fuentes, (2008): "La ética y la deontología de los medios en el tratamiento de la inmigración", en A.M. BAÑón HERNÁNDEZ; J. ForNIELES ALCARAZ (coords.), Manual sobre Comunicación e Inmigración, Tercera Prensa, 2008, pp. 153-180.

\title{
RESUMEN
}

El artículo revisa el estado actual de tratamiento del mundo de la inmigración en España, en los medios de comunicación, detallando los fallos fundamentales en la cobertura de asuntos relacionados con los inmigrantes, en los que las visiones estereotipadas, discriminatorias y negativas aparecen constantemente. Tras revisar el contenido de los diversos códigos y manuales de ética profesional en este sector, se indican líneas de actuación práctica y recomendaciones profesionales para mejorar la representación y la situación social completa de los inmigrantes en nuestro país.

Palabras clave: ética informativa, inmigración, representación en los medios, práctica profesional periodística, desarrollo social.

\begin{abstract}
The paper reviews the current state of treatment of the immigration world in Spain, its representing image in the media, detailing the fundamental flaws in coverage of issues related to immigrants, in which stereotypical, discriminatory and negative visions constantly appear. After reviewing the content of the various codes and manuals of professional ethics in this sector, the author indicates some lines of practical action and professional recommendations to improve the representation and full social situation of immigrants in our country.
\end{abstract}

Key words: information ethics, immigration, representation in the media, practical professional journalism, development social.

\section{RÉSUMÉ}

L'article passe en revue l'état actuel du traitement du monde de l'immigration en Espagne, dans les médias, détaillant les échecs fondamentaux dans la couverture des questions liées aux immigrants comme les stéréotypes, visions discriminatoires et négatives que apparaissent constamment. Après avoir examiné le contenu des différents codes et manuels de l'éthique professionnelle dans ce secteur, l' auteur indique les lignes d'action pratique et recommandations professionnelles afin d'améliorer la représentation et la situation sociale des immigrés dans notre pays.

Mots clé: éthique de l'information, de l'immigration, de représentation dans les médias, le journalisme professionnel pratique, développement social. 